\title{
Determination of the solution structures of melamine-based bis- and tris(macrocyclic) ligand copper(II) complexes
}

Peter Comba, ${ }^{*}$ Yaroslav D. Lampeka, ${ }^{b}$ Alexander I Prikhod 'ko, ${ }^{a}$ and Gopalan Rajaraman ${ }^{a}$

\author{
a) Universität Heidelberg, Anorganisch-Chemisches Institut, \\ INF 270, D-69120 Heidelberg, Germany \\ Phone: +49-6221-548453, Fax: +49-6226-548453, \\ e-mail: peter.comba@aci.uni-heidelberg.de
}

b) L.V. Pisarzhevsky Institute of Physical Chemistry, National Academy of Science of the Ukraine, Prospekt Nauki 31, 02039 Kiev 39, Ukraine

\section{Supplementary Material}


Figure S1. Data of the variable temperature magnetic susceptibility studies of $\left[\mathrm{Cu}_{2}\left(\mathrm{~L}^{2}\right)\left(\mathrm{OClO}_{3}\right)_{4}\right] \cdot$
$\mathrm{H}_{2} \mathrm{O} \cdot \mathrm{CH}_{3} \mathrm{OH}$

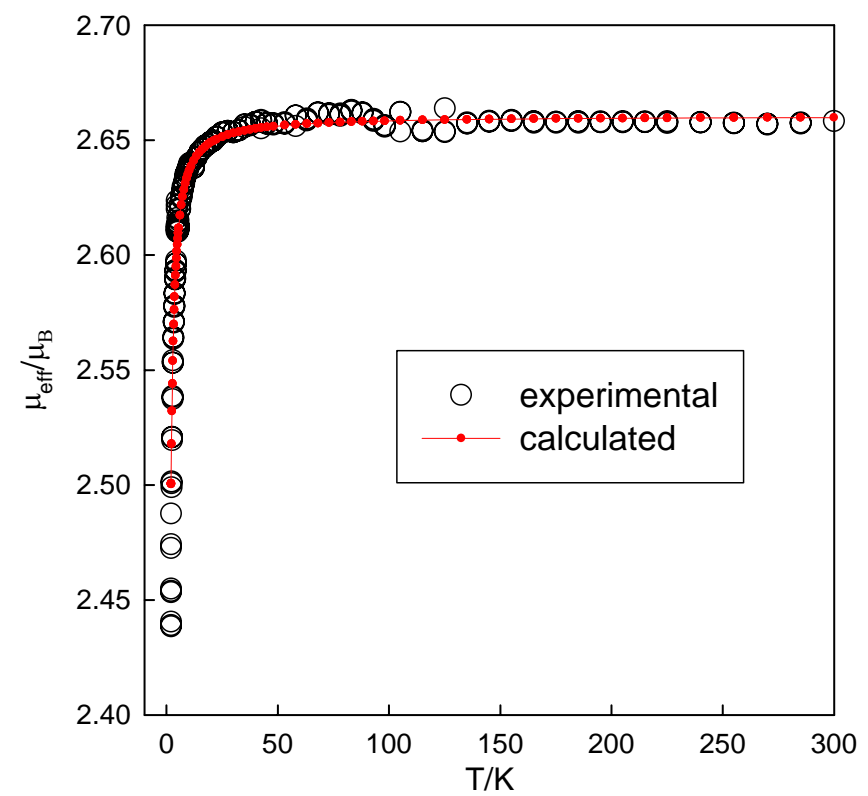

The best fit was obtained using the following parameters (the R-factor is 0.02 ):

$J=-0.453 \mathrm{~cm}^{-1}, \mathrm{~g}_{\mathrm{z}}=2.1716$. (the discontinuity around $100 \mathrm{~K}$ is due to a temporary instability of the magnetometer during the measurements)

For fitting only the isotropic intramolecular exchange interaction $(J)$ is considered. In the crystal structure the intermolecular $\mathrm{Cu} . . \mathrm{Cu}$ distances were in the range of 7.9 to $14.5 \AA$. Some of the distances are similar to the intra $\mathrm{Cu} . . . \mathrm{Cu}$ distances. Therefore, one may need to consider intermolecular exchange $(j$ ') for the fitting. However, the magnitude of $j$ ' is expected to be smaller than $J$ because these interactions are pure through space dipolar interactions. also, the $J$ value obtained from fitting is only a rough estimate because these $J$ values are too small to be estimated accurately by magnetic susceptibility measurements. Accurate estimates of $J$ are derived from EPR simulations (in solution) and they are very different from the ones obtained in the solid. Therefore addition of intermolecular exchange has not been considered in our model for number of reasons a) this will not help us to improve our fits b) even if it is 
included one can not trust the magnitude of the values obtained here $j$ ' c) this parameter cannot be calculated independently with DFT calculations. The similar arguments apply also to the trinuclear complexes. 
Figure S2.

Data of the variable temperature magnetic susceptibility studies of syn-syn

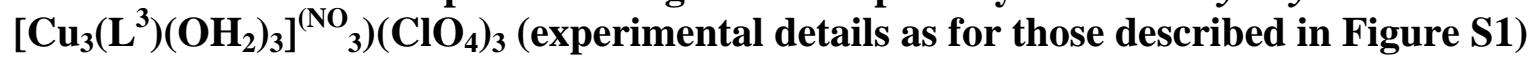

Cu3L4

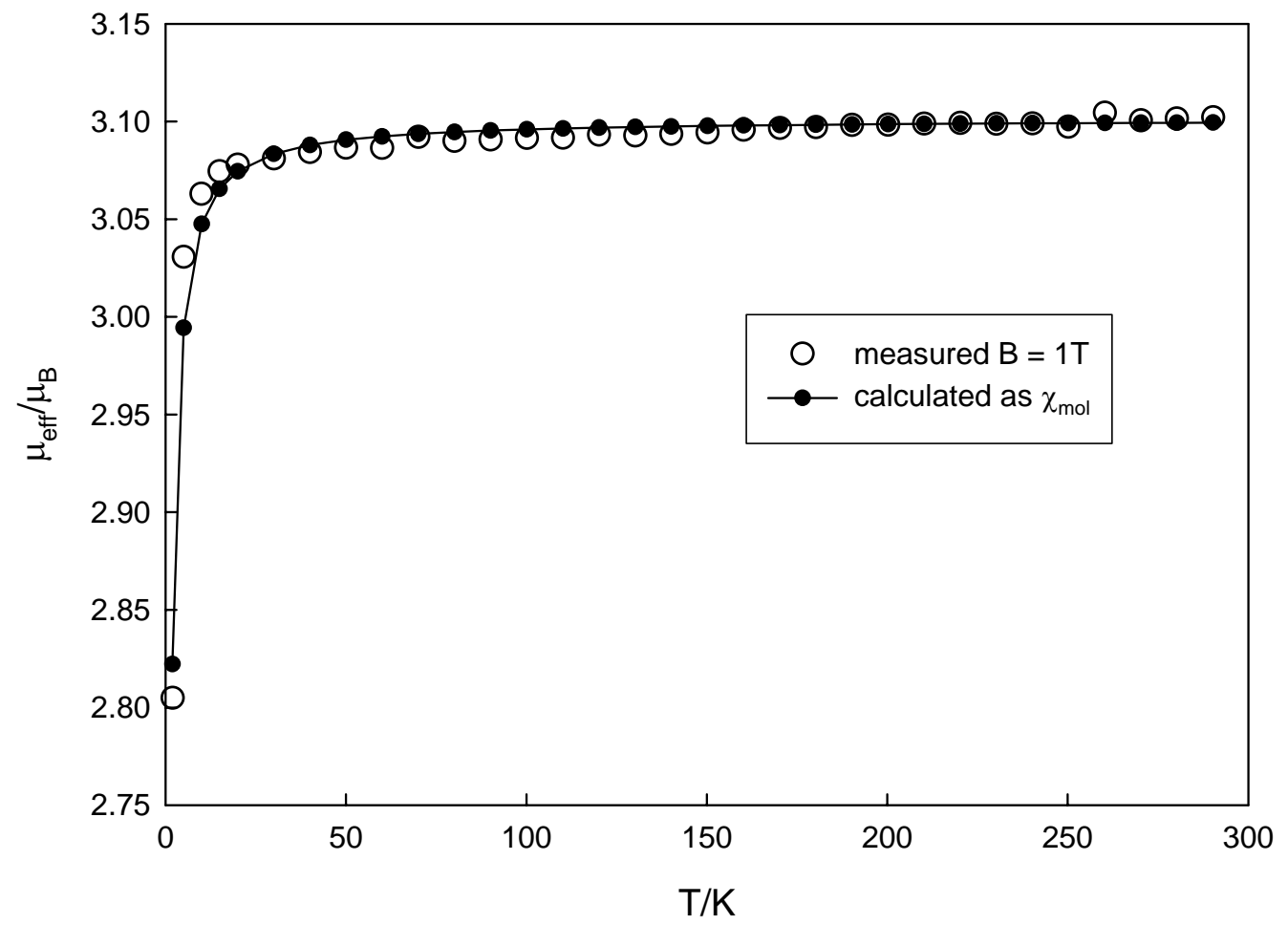

The best fit was obtained using the following parameters: (the R-factor is 0.014):

The Hamiltonian used is $H=-J\left(S_{1} S_{2}+S_{1} S_{3}+S_{2} S_{3}\right)$, and the $J$ value obtained is $-0.477 \mathrm{~cm}^{-1}$ with the $\mathrm{g}_{\mathrm{z}}=2.0668$. 
Figure S3.

Stabilization of the syn,syn isomer of $\left[\mathrm{Cu}_{3}\left(\mathrm{~L}^{3}\right)\right]^{6+}$.

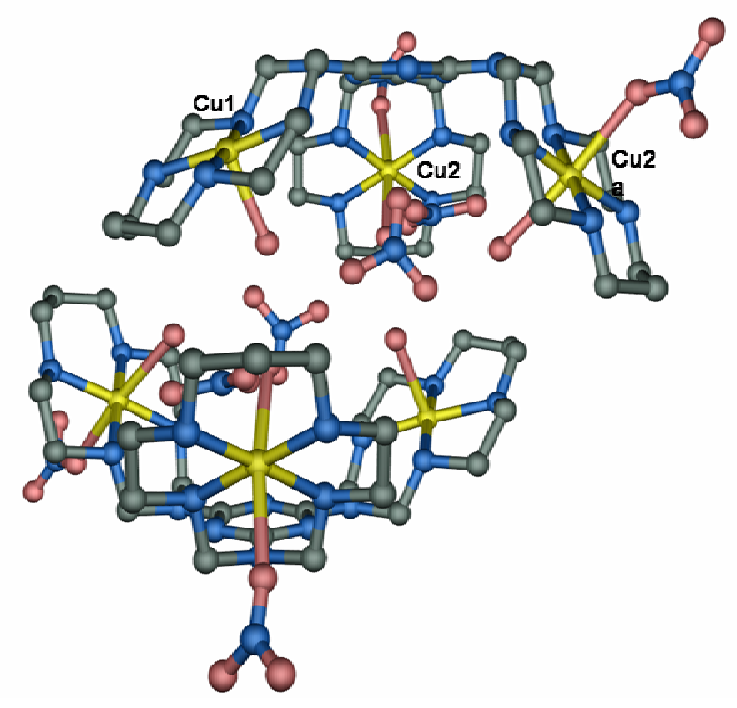

Plot of the crystal structure of syn, syn $\left[\mathrm{Cu}_{3}\left(\mathrm{~L}^{3}\right)\left(\mathrm{OH}_{2}\right)_{3}\right]\left(\mathrm{NO}_{3}\right)_{3}\left(\mathrm{ClO}_{4}\right)$, demonstrating possible hydrogen bonding interactions and the influence of anion binding.

Figure S4.

Further details on the EPR spectra of the trinuclear compound.

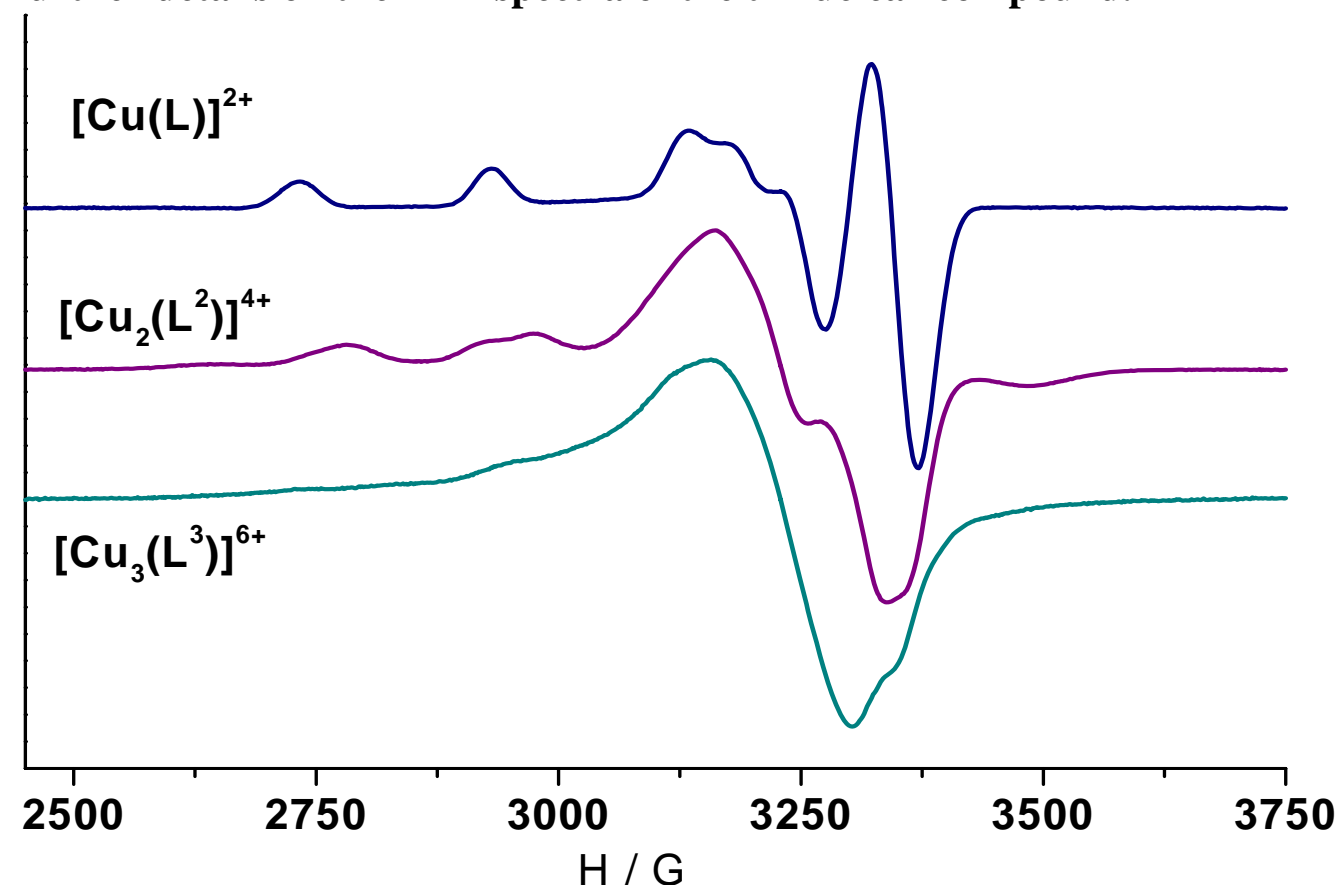

Frozen solution (130 K) EPR spectra of the mono-, bis- and tris-(macrocyclic) ligand copper(II) complexes in DMF: $\mathrm{H}_{2} \mathrm{O}$ solvent mixtures. 
The spectra in Figure S4 $\left(\mathrm{DMF} / \mathrm{H}_{2} \mathrm{O}\right.$ glass) need to be compared with Figure $3\left(\left[\mathrm{Cu}_{2}\left(\mathrm{~L}^{2}\right)\right]^{4+}\right)$ and Figure $6\left(\left[\mathrm{Cu}_{3}\left(\mathrm{~L}^{3}\right)\right]^{6+}\right)$, both in $\mathrm{DFM} / \mathrm{MeCN}$ glasses, as well as a spectrum earlier reported ${ }^{10}$ for $\left[\mathrm{Cu}_{3}\left(\mathrm{~L}^{3}\right)\right]^{6+}\left(\mathrm{DMF} / \mathrm{H}_{2} \mathrm{O}\right)$. The differences between our DMF/MeCN and the $\mathrm{DMF} / \mathrm{H}_{2} \mathrm{O}$ spectra are that the former are better resolved. Apart from that all features of the spectra of each compound are basically identical. The earlier reported spectrum ${ }^{10}$ of $\left[\mathrm{Cu}_{3}\left(\mathrm{~L}^{3}\right)\right]^{6+}$ is strikingly different from those in Figure 6 and the $\left[\mathrm{Cu}_{3}\left(\mathrm{~L}^{3}\right)\right]^{6+}$ spectrum in Figure S4 (the same solvent) but it is practically superimposable with the $\left[\mathrm{Cu}_{2}\left(\mathrm{~L}^{2}\right)\right]^{4+}$ spectrum in Figure S4 (and also identical but less well resolved than the experimental spectrum in Figure 3). Our obvious interpretation is that the EPR spectrum reported in reference 10 is that of the dinuclear and not that of the trinuclear complex. A reviewer of our manuscript pointed out that the differences between the earlier reported ${ }^{10}$ and our spectra might be due to the stabilization of either the syn,anti or the syn,syn conformations in various solvent mixtures. Due to the small energy difference this is a valuable expectation which we have carefully checked by EPR spectra in various solvents and their simulation. Unfortunately we have not found any indication for this. However, due to the poor resolution (at least for the trinuclear compound) we cannot exclude the presence of some amount of the other isomer. We are certain that the syn and syn,syn isomers are the major (if not only) component in solution and believe that this is due to stabilization by hydrogen bonding. It is clear, however, that the earlier reported spectrum is erroneous.

Table S1. Computed EPR g- A- and a- tensor values using non-standard B38LYP functional (the $A$ and a values are in $10^{-4} \mathrm{~cm}^{-1}$ ).

\begin{tabular}{|c|c|c|}
\hline parameter & simulations & MM-B38LYP \\
\hline$g_{\perp}$ & 2.041 & 2.053 \\
\hline $\mathrm{g}_{\|}$ & 2.191 & 2.183 \\
\hline $\mathrm{A}_{\mathrm{x}}$ & 26.5 & -11.0 \\
\hline $\mathrm{A}_{\mathrm{y}}$ & 26.5 & -11.5 \\
\hline $\mathrm{A}_{\mathrm{z}}$ & 200.0 & 224.5 \\
\hline$a^{N 1}{ }_{x}$ & & 8.5 \\
\hline$a^{N 1} y$ & & 8.6 \\
\hline$a^{N 1}{ }_{z}$ & & 13.2 \\
\hline$a^{N 2} x$ & & 8.5 \\
\hline$a^{N 2} y$ & & 8.6 \\
\hline$a^{\mathrm{N} 2} \mathrm{z}$ & & 13.2 \\
\hline$a^{N 3} x$ & & 8.1 \\
\hline$a^{N 3} y$ & & 8.2 \\
\hline$a^{N 3} z$ & & 12.8 \\
\hline$a^{N 4}$ & & 8.4 \\
\hline $\mathrm{a}^{\mathrm{N} 4} \mathrm{y}$ & & 8.2 \\
\hline$a^{N 4}$ & & 12.7 \\
\hline
\end{tabular}


Our recent DFT studies on $\mathrm{Cu}(\mathrm{II})$ complexes of tetradentate bispidine type ligand suggest that there is no unique functional available to calculate all the spectroscopic parameters accurately. ${ }^{17}$ A better estimate of the g-tensor is to use a hybrid functional with $38 \% \mathrm{HF}$ correlation. Reasonably accurate $\mathrm{g} \|$ values are obtained at the expense of an overestimation of $\mathrm{A}_{\mathrm{z}}$ using the non-standard B38LYP functional. 